\title{
THE ROLE OF ZONULIN IN THE DEVELOPMENT OF LIVER FIBROSIS IN OBESE ADOLESCENTS
}

10.36740/WLek202101115

\author{
Liudmyla K. Parkhomenko, Larysa A. Strashok, Margaryta A. Khomenko \\ KHARKIV MEDICAL ACADEMY OF POSTGRADUATE EDUCATION, KHARKIV, UKRAINE
}

\begin{abstract}
The aim: To study the relationship between zonulin level and PNFI (pediatric non-alcoholic fatty liver disease fibrosis index) in obese adolescents.

Material and methods: A total of fifty-nine obese subjects aged 12-17 years and thirteen healthy subjects were included in the study. Clinical, biochemical parameters, including serum zonulin, were examined and abdominal ultrasound examination was performed. For the assessment of liver fibrosis PNFI was calculated.

Results: According to ultrasound examination $71,2 \%$ of obese adolescents had non-alcoholic fatty liver disease (NAFLD). Calculation of PNFI showed that $25,4 \%$ of obese subjects had fibrotic processes in the liver. Obese adolescents had significantly higher zonulin levels compared to normal weight peers $-91,8 \pm 3,1$ vs $15,9 \pm 5,1$ respectively $(p<0,01)$. A significant positive correlation was established between zonulin levels and such parameters as body mass index, waist circumference / height ratio, triglycerides, very low-density lipoprotein cholesterol, insulin, homeostasis model assessment of insulin resistance, PNFI $(p<0,05)$.

Conclusions: The level of zonulin increases with an increase of the index for evaluating liver fibrosis (PNFI) in obese adolescents. This may indicate the effect of the state of the intestinal barrier on the development and progression of obesity-related liver pathology, namely NAFLD, in obese adolescents.
\end{abstract}

KEY WORDS: obesity, NAFLD, zonulin, adolescents

\section{INTRODUCTION}

\section{THE PREVALENCE OF OBESITY AND NAFLD}

Today, obesity is becoming one of the most common non-communicable diseases in children. According to WHO, over 340 million adolescents and children between the ages of 5 and 19 and about 41 million children under 5 years of age are overweight or obese [1]. Obesity, type 2 diabetes mellitus, hypertension, atherogenic dyslipidemia, and nonalcoholic fatty liver disease (NAFLD) are linked by a common pathogenesis and are components of the metabolic syndrome [2]. Pathological changes in NAFLD are characterized by a spectrum of conditions associated with the presence of vesicular steatosis of the liver. It may eventually progress to non-alcoholic steatohepatitis (NASH), fibrosis, and cirrhosis, which with high probability leads to the development of hepatocellular carcinoma in adults [3]. The prevalence of NAFLD in children and adolescents is growing in parallel with the obesity epidemic in the world [4]. This is confirmed by data from a recent meta-analysis, which revealed that the prevalence of NAFLD in children and adolescents was $7,6 \%$ in the general population and $34,2 \%$ in obese patients [5].

Recent data indicate that among all characteristic histological changes in the liver in NAFLD, fibrosis has the highest prognostic value for the progression of the disease and the development of complications [6]. The «gold stan- dard» for assessing liver fibrosis is a biopsy, however, due to the fact that the procedure is technically demanding and involves the risk of complications, the use of non-invasive methods for assessing liver fibrosis in obese children is a topical issue in pediatrics. Today, a number of non-invasive tests have been developed to assess fibrotic changes in the liver, which are already used in pediatric practice [7]. The PNFI (pediatric NAFLD fibrosis index) developed specifically for evaluating liver fibrosis in childhood is of particular interest [8].

\section{THE RELATIONSHIP BETWEEN INTESTINAL} BARRIER INTEGRITY, OBESITY AND NAFLD

Qualitative and quantitative changes in the diet of obese children and adolescents, namely, the use of food rich in fats and easily digestible carbohydrates, decreased intake of fiber, etc., significantly affect the intestinal biocenosis and lead to changes in the composition of the intestinal microbiota [9]. In recent years, there has been an increasing number of studies demonstrating a close relationship between the intestinal microbiota and the liver. This natural connection is called the "gut-liver axis» [10]. New data on the relationship between the intestines and liver provide a basis for revising the understanding of the pathogenesis of a such obesity-associated pathology as NAFLD. Based on recent studies a «multiple parallel hits» hypothesis has 
been proposed, according to which the pathogenesis of NAFLD involves the influence of various factors on the liver tissue, including the gut microbiota and the products of its interaction with the host organism against the background of oxidative stress [11].

Dysbiosis is considered a trigger for increased synthesis of zonulin, a protein that is one of the regulators of intestinal permeability by modulating intercellular tight junctions. Human zonulin is a recently discovered $47-\mathrm{kDa}$ protein that is structurally similar to Vibrio cholerae's zonula occludens toxin [12]. Zonulin is thought to activate the epidermal growth factor receptor (EGFR) through direct binding and / or through a protease-activated receptor (PAR2). This leads to the expansion of intercellular tight junctions in the intestinal wall and, as a result, to increased permeability of the intestinal barrier (the so-called «leaky gut syndrome») [13]. Many components of microbial cells, including the lipopolysaccharide of gram-negative bacteria, flagelin, linoleic acid, and peptidoglycans are so-called pathogen-associated molecular patterns that are recognized by specific Toll-and Nod-like receptors. Under normal conditions, a small amount of bacterial products from the intestine enters the liver through the portal circulation, where they are eliminated by Kupfer cells [14]. Increased permeability of the intestinal barrier leads to an excessive flow of bacteria and their products to the bloodstream and liver, and thus, through stimulation of Toll - and Nod-like receptors, causes activation of signalling cascades and the release of a large number of cytokines and chemokines. This triggers the process of chronic low-grade inflammation, which gives impulse to the progression of obesity and its complications [15].

Recently published studies have shown the highest levels of circulating zonulin in obese adults compared to healthy ones [15]. The results of intestinal permeability studies confirm the role of intestinal barrier dysfunction in the development and progression of not only obesity but also associated pathology. Miele et al were among the first to provide evidence that NAFLD in adult patients is associated with increased intestinal permeability which is caused by violation of intercellular tight junctions [16]. Current research shows that changes in intestinal permeability in obesity and NAFLD are already present in children and adolescents as well. Küme $\mathrm{T}$ et al in their work showed that obese children had significantly higher zonulin levels than their healthy peers [17]. Similar data were obtained in the study by Kim I. N. et al. [18]. Zonulin levels were significantly higher in obese children with NAFLD in the work by L. Pacifico et al. [19]. The levels of this protein was also higher in children with NAFLD compared to the control group in studies conducted in Turkey [20] and Italy [21].

These data suggest the possibility of a link between the composition of the gut microbiota, violation of the intestinal barrier and increased levels of endotoxemia, which leads to chronic low-grade inflammation and contributes to the development of obesity and its complications [10, $11,14]$. However, there are fewer such studies in children and adolescents than in adults, making the question of the impact of disturbed intestinal permeability in the pathogenesis of obesity and NAFLD relevant.

\section{THE AIM}

To study the relationship between zonulin level and PNFI in obese adolescents.

\section{MATERIALS AND METHODS}

\section{STUDY SUBJECTS}

The study involved fifty-nine obese adolescents aged 12-17 years (45,8\% - boys and 54,2\% - girls) who were treated at the SI «Institute for Children and Adolescent Health Care at the National Academy of Medical Sciences of Ukraine» and 13 healthy children with normal body mass index (BMI) of similar age and gender. The diagnosis of obesity was established according to the ICD-10. NAFLD was diagnosed on the basis of an abdominal ultrasound examination. Other causes of liver disease, including viral infections (cytomegalovirus and Epstein-Barr virus, hepatitis A, E and G), autoimmune hepatitis, Wilson's disease, cystic fibrosis, celiac disease, etc. were excluded in all patients.

Anthropometric examination included measurement of standing height, body weight, waist circumference (WC), hip circumference (HC), calculation of the $\mathrm{WC} / \mathrm{HC}$ ratio, the $\mathrm{WC} /$ height ratio (indicators of abdominal obesity), body mass index (BMI) using the formula: $\mathrm{BMI}=$ body weight $(\mathrm{kg}) /$ height $\left(\mathrm{m}^{2}\right)$. The BMI was assessed according to the standards of WHO. The subjects were treated according to the Declaration of Helsinki and the study was approved by the Ethics Committee of the Kharkiv Medical Academy of Postgraduate Education (No 5, November 2019), Kharkiv, Ukraine. All subjects gave their written informed consent before entering the study.

\section{LABORATORY AND INSTRUMENTAL METHODS OF RESEARCH}

The venous blood samples were collected after 10-12 hours of night fasting. The concentrations of serum glucose, immunoreactive insulin (IRI), alanine aminotransferase (ALT), aspartate aminotransferase (AST), gamaglutamyltranspeptidase (GGTP), total bilirubin, triglycerides (TG), total cholesterol (TC), high-density lipoprotein cholesterol (HDL-C) were measured. The kits which were used in the study were EKF-diagnostic GmbH (glucose), DRG (IRI), Spainlab (ALT, AST, total bilirubin, TC, TG, HDL-C, GGTP) according to the manufacturer's instructions. The concentrations of low-density lipoprotein cholesterol (LDL-C) and very low-density lipoprotein cholesterol (VLDL-C) were calculated using Friedewald formula: $\mathrm{LDL}-\mathrm{C}(\mathrm{mmol} / \mathrm{l})=\mathrm{TC}$ $(\mathrm{mmol} / \mathrm{l})$ - HDL-C $(\mathrm{mmol} / \mathrm{l})$ - TG $(\mathrm{mmol} / \mathrm{l}) / 2,2$; VLDL-C $(\mathrm{mmol} / \mathrm{l})=\mathrm{TG}(\mathrm{mmol} / \mathrm{l}) / 2,2[22]$. Insulin resistance was assessed by calculating the homeostasis model assessment of insulin resistance (HOMA-IR): HOMA-IR = fasting glucose $(\mathrm{mmol} / \mathrm{l}) \times$ fasting IRI $(\mu \mathrm{IU} / \mathrm{ml}) / 22,5$ [23]. Part of the col- 
Table I. The characteristic of clinical and laboratory parameters of the examined adolescents (mean $\pm \mathrm{SE}$ ).

\begin{tabular}{|c|c|c|}
\hline Parameters & Obese subjects $(n=59)$ & Control subjects $(n=13)$ \\
\hline Age (years) & $14,53 \pm 0,21$ & $14,46 \pm 0,38$ \\
\hline Height (cm) & $168,06 \pm 1,24$ & $168,69 \pm 1,97$ \\
\hline Weight (kg) & $87,41 \pm 2,03$ & $54,07 \pm 2,14^{* *}$ \\
\hline BMI (kg/m2) & $30,82 \pm 0,49$ & $18,98 \pm 0,45^{* *}$ \\
\hline$W C(\mathrm{~cm})$ & $93,13 \pm 1,27$ & $65,54 \pm 1,08^{* *}$ \\
\hline $\mathrm{HC}(\mathrm{cm})$ & $111,98 \pm 0,97$ & $89,61 \pm 1,72^{* *}$ \\
\hline $\mathrm{WC} / \mathrm{HC}(\mathrm{cm})$ & $0,83 \pm 0,01$ & $0,72 \pm 0,01^{* *}$ \\
\hline WC / Height $(\mathrm{cm})$ & $0,56 \pm 0,01$ & $0,34 \pm 0,01^{* *}$ \\
\hline AST (U/L) & $26,52 \pm 1,41$ & $25,23 \pm 1,33$ \\
\hline $\operatorname{ALT}(U / L)$ & $27,26 \pm 1,56$ & $21,53 \pm 1,54^{*}$ \\
\hline GGTP (U/L) & $23,13 \pm 1,04$ & $16,34 \pm 1,16^{* *}$ \\
\hline Total bilirubin $(\mu \mathrm{mol} / \mathrm{l})$ & $16,55 \pm 0,81$ & $13,74 \pm 0,93^{*}$ \\
\hline $\mathrm{TC}(\mathrm{mmol} / \mathrm{l})$ & $5,17 \pm 0,11$ & $4,23 \pm 0,21^{* *}$ \\
\hline $\mathrm{TG}(\mathrm{mmol} / \mathrm{l})$ & $1,45 \pm 0,08$ & $0,85 \pm 0,09^{* *}$ \\
\hline LDL-C (mmol/l) & $2,89 \pm 0,11$ & $2,26 \pm 0,17^{* *}$ \\
\hline VLDL-C (mmol/l) & $0,65 \pm 0,03$ & $0,38 \pm 0,08^{* *}$ \\
\hline $\mathrm{HDL}-\mathrm{C}(\mathrm{mmol} / \mathrm{l})$ & $1,61 \pm 0,05$ & $1,64 \pm 0,19$ \\
\hline Glucose (mmol/l) & $4,77 \pm 0,06$ & $4,34 \pm 0,09 * *$ \\
\hline IRI $(\mu \mathrm{IU} / \mathrm{ml})$ & $24,71 \pm 1,78$ & $11,52 \pm 0,71^{* *}$ \\
\hline HOMA-IR & $5,26 \pm 0,37$ & $2,21 \pm 0,12^{* *}$ \\
\hline Zonulin (ng/ml) & $91,89 \pm 3,12$ & $15,96 \pm 5,1^{* *}$ \\
\hline
\end{tabular}

Note: BMI - body mass index, WC - waist circumference, HC - hip circumference, WC/HC - the ratio of waist circumference to hip circumference, WC/ height - the ratio of waist circumference to height, AST - aspartate aminotransferase, ALT - alanine aminotransferase, GGTP-gamaglutamyltranspeptidase, TC - total cholesterol, TG - triglycerides, VLDL-C - very low-density lipoprotein cholesterol, LDL-C - low-density lipoprotein cholesterol, HDL-C - highdensity lipoprotein cholesterol, IRI - immunoreactive insulin, HOMA-IR - homeostasis model assessment of insulin resistance.

${ }^{*}-p<0,05,{ }^{* *}-p<0,01$.

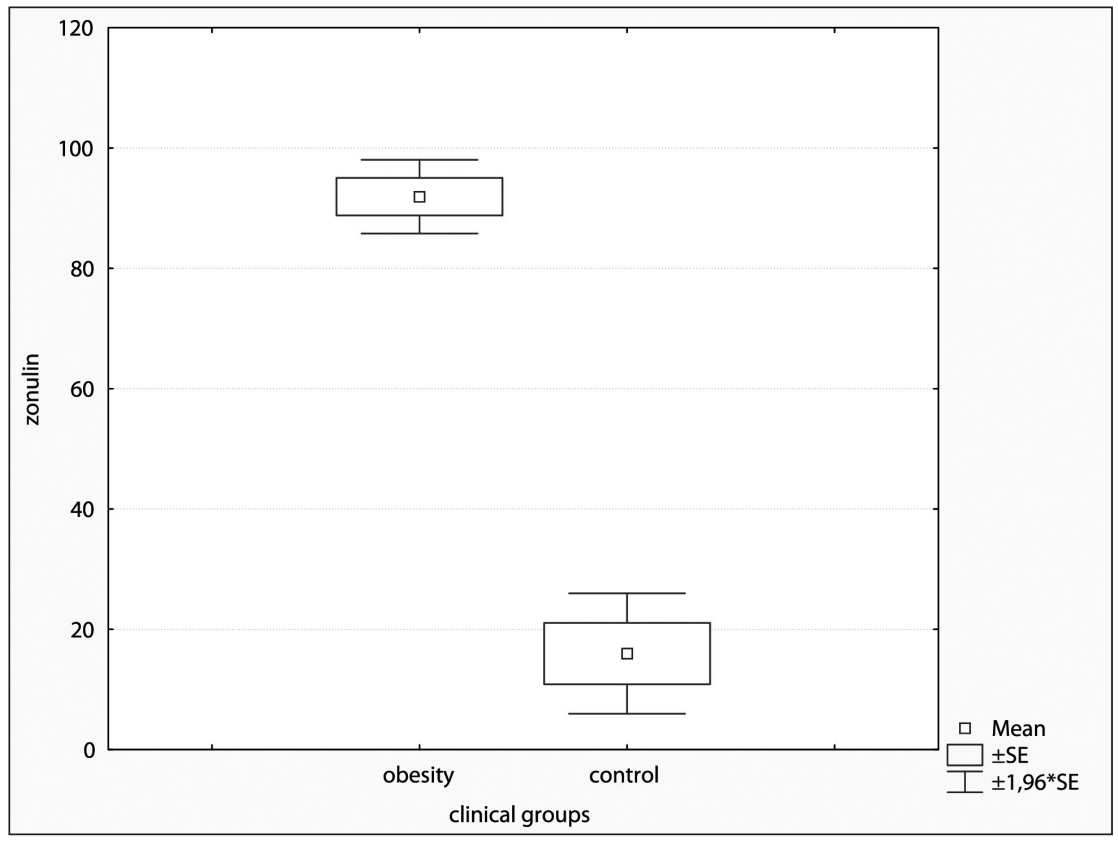

Fig.1. Zonulin levels in obese and healthy subjects

lected blood was centrifuged and stored at $-20^{\circ} \mathrm{C}$ for further analysis of zonulin levels by using an ELISA kit (Elabscience) according to the manufacturer's instructions. Ultrasound examination was performed on an empty stomach using an «ULTIMA SM-50» with a 3,5-5 MHz convex transducer and a 7,5-10 $\mathrm{MHz}$ linear transducer. 


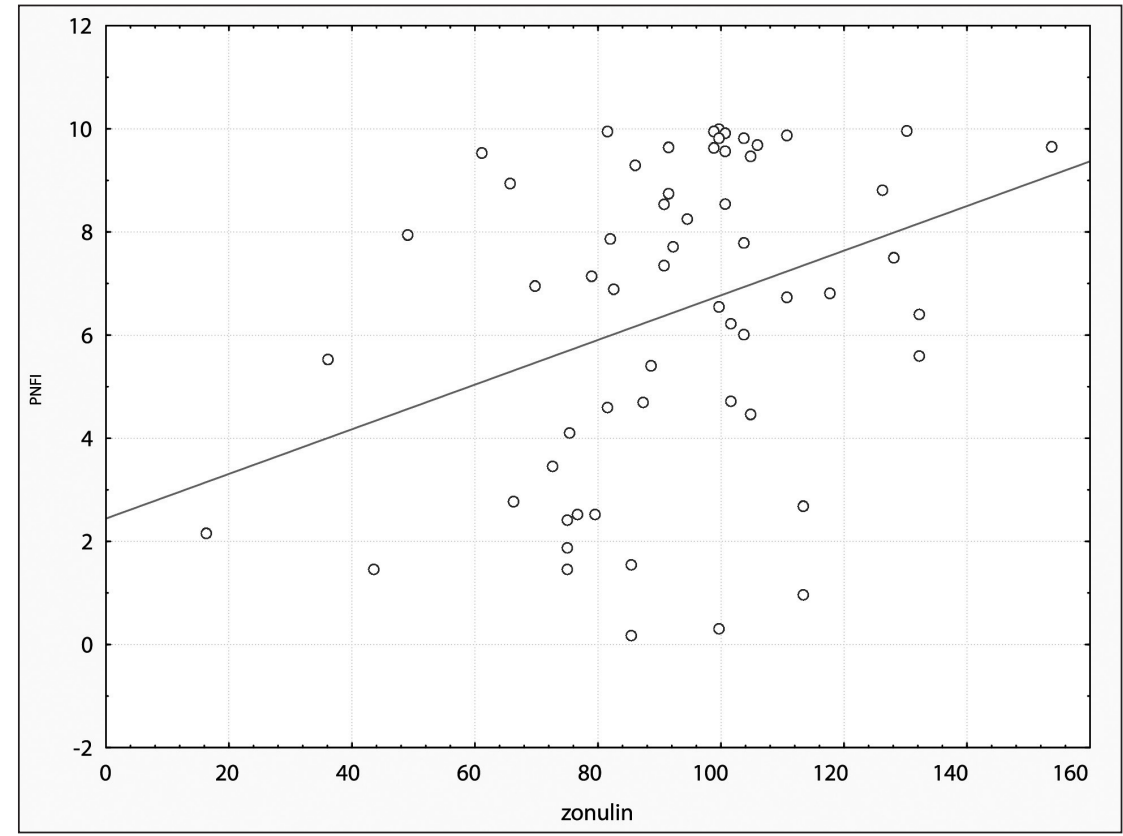

Fig. 2. Association between zonulin and PNFI in obese adolescents

\section{CALCULATION OF PNFI}

The PNFI (pediatric NAFLD fibrosis index) was calculated on the basis of TGlevels, age and WC: $\mathrm{PNFI}=1 /\left(1+\mathrm{e}^{-\mathrm{lp}}\right) \times 10$, where lp $=6,539 \times \log _{\mathrm{e}}$ [age (years)] $+0,207 \times \mathrm{WC}(\mathrm{cm})+$ $1,957 \times \log _{e}[\mathrm{TG}(\mathrm{mg} / \mathrm{dl})]-10,074$. According to the method, the value of the index $\geq 9$ indicates the presence of fibrotic changes in the liver of the patient [8].

\section{STATISTICAL ANALYSIS}

Statistical analyses were performed by Statistica 6.0. The data were expressed as mean \pm SE. The distribution of the data was evaluated with the Kolmogorov-Smirnov test. Differences between groups were tested using Student's $\mathrm{t}$-test for the variables conforming to the Gaussian distribution and Mann-Whitney U test for non-Gaussian variables. The data was analyzed by linear correlation. A $p$-value $<$ 0,05 was considered statistically significant.

\section{RESULTS AND DISCUSSION}

The study revealed that $79,7 \%$ of patients had increased appetite, 52,5\% - abdominal pain, $40,7 \%$ - belching, $37,2 \%$ - heartburn, 30,5\% - nausea, $28,8 \%$ - flatulence, $23,7 \%$ - constipation, and $15,2 \%$ had loose stools. Objective examination of patients revealed pain in the right hypochondrium in $40,6 \%$ of adolescents, in the epigastrium in $33,8 \%$, liver enlargement was noted in $79,6 \%$. The characteristic of clinical and laboratory parameters of the examined adolescents is presented in Table I.

As expected among the anthropometric parameters significantly higher in obese adolescents were weight, $\mathrm{BMI}, \mathrm{WC}, \mathrm{HC}, \mathrm{WC} / \mathrm{HC}$ ratio, $\mathrm{WC} /$ height. There was no significant difference in age and height between the groups. Among the laboratory parameters the levels of IRI, glucose, HOMA-IR, total bilirubin, total cholesterol, TG, LDL-C,
VLDL-C, GGTP and zonulin were significantly higher in obese adolescents (Figure 1). It should be menshioned that high GGTP levels are associated with fibrotic changes in the liver, which was noted in the report of the ESPGHAN Hepatology Committee [24]. The AST levels did not differ significantly between the groups. The mean ALT level was higher in obese adolescents, although it remained within the age range. The results obtained in our study confirm the opinion that children with obesity and NAFLD even with normal or slightly elevated ALT levels may already have significant histological abnormalities, including fibrosis [24, 25].

NAFLD was diagnosed in $71,2 \%$ of obese adolescents according to ultrasound examination. The calculation of PNFI showed the presence of fibrotic changes in a liver in $25,4 \%$ of obese adolescents. Correlation analysis revealed a significant and positive link between zonulin levels and such indicators as BMI $(\mathrm{r}=0,37 ; \mathrm{p}=0,009)$, WC/height $(\mathrm{r}=0,39 ; \mathrm{p}=0,002), \mathrm{TG}(\mathrm{r}=0,28 ; \mathrm{p}=0,039)$, VLDL-C $(\mathrm{r}=0,28 ; \mathrm{p}=0,039)$, IRI $(\mathrm{r}=0,26 ; \mathrm{p}=0,045)$, HOMA-IR $(r=0,27 ; p=0,042)$, PNFI $(r=0,34 ; p=0,008)$ (Figure 2$)$.

The present study revealed a significantly higher serum zonulin levels in obese adolescents compared to healthy peers. Our findings are consistent with previous studies in both adults [15] and children, adolescents [17, 18, 19, 20, 21].

There were a significant positive correlation links between zonulin levels and levels of TG, VLDL-C, IRI, HOMA-IR, which demonstrate the association between the violation of lipid and carbohydrate metabolism and increased intestinal permeability in obesity. There was also a significant positive correlation between zonulin levels and such anthropometric parameters as BMI, WC / height ratio. This confirms the destructive effect of obesity, especially abdominal type of it, on the state of the intestinal barrier and the development of comorbid pathology. We found a significant positive correlation between zonulin levels 
and the index for assessing liver fibrosis PNFI, which may indicate the influence of increased intestinal permeability on the development of NAFLD in obese adolescents.

\section{CONCLUSIONS}

1. NAFLD was diagnosed in $2 / 3$ of obese adolescents, and in $1 / 4$ the presence of fibrotic changes of a liver according to the PNFI was noted.

2. A significantly higher serum zonulin levels were observed in obese adolescents compared to healthy peers.

3. The level of zonulin increases in parallel with the PNFI in obese adolescents. This fact may be an evidence of the influence of intestinal permeability on the development and progression of NAFLD. A significant positive correlation between zonulin levels and such parameters as BMI, WC / height, TG, VLDL-C, insulin, HOMA-IR was noted.

4. An in-depth understanding of the causal link underlying the identified data is needed. This will lead to improved diagnosis of NAFLD at an early stage and enable the development of new therapeutic approaches aimed at regulating the gut microbiota in obese children and adolescents.

\section{REFERENCES}

1. Report of the Commission on Ending Childhood Obesity. Implementation plan: executive summary. Geneva: World Health Organization. 2017. https://apps.who.int/iris/bitstream/handle/10665/259349/WHONMH-PND-ECH0-17.1-eng.pdf?sequence $=1$.

2. Wittcopp C., Rushika C. Metabolic syndrome in children and adolescents. Pediatrics in review. 2016;37(5):193-202. doi.org/10.1542/pir.20140095.

3. Bush H., Golabi P., Younossi Z.M. Pediatric non-alcoholic fatty liver disease. Children (Basel). 2017;4(6):48. doi: 10.3390/children4060048.

4. Xu S., Xue Y. Pediatric obesity: Causes, symptoms, prevention and treatment. Exp Ther Med. 2016;11(1):15-20. doi:10.3892/ etm.2015.2853.

5. Anderson E.L., Howe L.D., Jones H.E., Higgins J.P. et al. The prevalence of non-alcoholic fatty liver disease in children and adolescents: a systematic review and meta-analysis. PLoS One. 2015;10(10):e0140908. doi: 10.1371/journal.pone.0140908.

6. Calzadilla Bertot L., Adams L.A. The Natural Course of Non-Alcoholic Fatty Liver Disease. Int J Mol Sci. 2016;17(5):774. doi:10.3390/ijms17050774.

7. Rudolph B., Bjorklund N., Ovchinsky N. et al. Methods to improve the noninvasive diagnosis and assessment of disease severity in children with suspected nonalcoholic fatty liver disease (NAFLD): Study design. Contemporary clinical trials. 2018;75:51-58. doi: 10.1016/j. cct.2018.10.012.

8. Nobili V., Alisi A., Vania A., Tiribelli C. et al. The pediatric NAFLD fibrosis index: a predictor of liver fibrosis in children with non-alcoholic fatty liver disease. BMC Med. 2009;7:21. doi:10.1186/1741-7015-7-21.

9. Panasevich M.R., Peppler W.T., Oerther D.B., Wright D.C. et al. Microbiome and NAFLD: potential influence of aerobic fitness and lifestyle modification. Physiol Genomics. 2017;49(8):385-399. doi: 10.1152/physiolgenomics.00012.2017.

10. Zhang X., Ji X., Wang Q., Zhong Li J. New insight into inter-organ crosstalk contributing to the pathogenesis of non-alcoholic fatty liver disease (NAFLD). Protein Cell. 2018;9(2):164-177. doi: 10.1007/s13238017-0436-0.
11. Fang Y.L., Chen H., Wang C.L., Liang L. Pathogenesis of non-alcoholic fatty liver disease in children and adolescence: From "two hit theory" to "multiple hit model". World J Gastroenterol. 2018;24(27):2974-2983. doi: 10.3748/wjg.v24.i27.2974.

12. Hendy 0.M., Elsabaawy M.M., Aref M.M., Khalaf F.M. et al. Evaluation of circulating zonulin as a potential marker in the pathogenesis of nonalcoholic fatty liver disease. Apmis. 2017;125(7):607-613. doi: 10.1111/apm.12696.

13. Fasano $A$. Zonulin and its regulation of intestinal barrier function: the biological door to inflammation, autoimmunity, and cancer. Physiological reviews. 2017;91(1):151-175. doi: 10.1152/physrev.00003.2008.

14. Leung C., Rivera L., Furness J.B., Angus P.W. The role of the gut microbiota in NAFLD. Nat Rev Gastroenterol Hepatol. 2016;13(7):412-25. doi: 10.1038/nrgastro.2016.85.

15. Ohlsson B., Orho-Melander M., Nilsson P.M. Higher levels of serum zonulin may rather be associated with increased risk of obesity and hyperlipidemia, than with gastrointestinal symptoms or disease manifestations. Int J Mol Sci. 2017;18(3). doi: 10.3390/ijms18030582.

16. Miele L., Valenza V., La Torre G. et al. Increased intestinal permeability and tight junction alterations in nonalcoholic fatty liver disease. Hepatology. 2009;49(6):1877-87. doi: 10.1002/hep.22848.

17. Küme T., Acar S., Tuhan H. et al. The relationship between serum zonulin level and clinical and laboratory parameters of childhood obesity. Journal of clinical research in pediatric endocrinology. 2017;9(1):31-38. doi: 10.4274/jcrpe.3682.

18. Kim Ji H., Heo J.S., Baek K.S. et al. Zonulin level, a marker of intestinal permeability, is increased in association with liver enzymes in young adolescents. Clinica Chimica Acta. 2018;481:218-224. doi: 10.1016/j. cca.2018.03.005.

19. Pacifico L., Bonci E., Marandola L., Romaggioli S. et al. Increased circulating zonulin in children with biopsy-proven nonalcoholic fatty liver disease. World J Gastroenterol. 2014;20(45):17107-14 doi: 10.3748/wjg.v20.i45.17107.

20. Çakır M., Aksel İşbilen A., Eyüpoğlu I. et al. Effects of long-term synbiotic supplementation in addition to lifestyle changes in children with obesity-related non-alcoholic fatty liver disease. Turk J Gastroenterol. 2017;28(5):377-383. doi: 10.5152/tjg.2017.17084.

21. Loffredo L., Zicari A.M., Perri L. et al. Does Nox2 Overactivate in Children with Nonalcoholic Fatty Liver Disease? Antioxid Redox Signal. 2019;30(10):1325-1330. doi: 10.1089/ars.2018.7596.

22. Friedewald W.T., Levy R.I., Fredrickson D.S. Estimation of the concentration of low-density lipoprotein cholesterol in plasma, without use of the preparative ultracentrifuge. Clin Chem. 1972;18:499-502.

23. Matthews D.R., Hosker J.P., Rudenski A.S., Naylor B.A. etal. Homeostasis mode assessment: insulin resistance and beta-cell function from fasting plasma glucose and insulin concentrations in man. Diabetologia. 1985;28(7):412-9.

24. Vajro P., Lenta S., Socha P. et al. Diagnosis of nonalcoholic fatty liver disease in children and adolescents: position paper of the ESPGHAN Hepatology Committee. Journal of pediatric gastroenterology and nutrition. 2012;54(5):700-713. doi: 10.1097/MPG.0b013e318252a13f.

25. Molleston J.P., Schwimmer J.B., Yates K.P. et al. Histological abnormalities in children with nonalcoholic fatty liver disease and normal or mildly elevated alanine aminotransferase levels. The Journal of pediatrics. 2014;164(4):707-713. doi: 10.1016/j.jpeds.2013.10.071.

\section{ORCID and contributionship:}

Liudmyla K. Parkhomenko: 0000-0002-4454-0979 A,E,F

Larysa A. Strashok: 0000-0002-9683-4776 ${ }^{A, C, D}$

Margaryta A. Khomenko: 0000-0003-4747-3828 ${ }^{B, C, D}$ 


\section{Conflict of interest:}

The Authors declare no conflict of interest.

\section{CORRESPONDING AUTHOR}

Margaryta A. Khomenko

Kharkiv medical academy of

Postgraduate education

58 Amosova Street, 61000 Kharkiv, Ukraine

tel: 0954171237

e-mail:kh.margaryta@gmail.com

Received: 13.03 .2020

Accepted: 07.10 .2020

A - Work concept and design, B - Data collection and analysis, C - Responsibility for statistical analysis,

D-Writing the article, E-Critical review, F-Final approval of the article 